\title{
THE DRUG TREATMENT OF HYPERPIESIA
}

\author{
BY \\ WILLIAM EVANS AND OWEN LOUGHNAN
}

From the Cardiac Department of the London Hospital

Received April 2, 1939

The more numerous the remedies for a disease the less likely that any will prove consistently helpful. Of the many drugs recommended for hyperpiesia (essential hypertension) there is no agreement on the best to employ, and none has gained any outstanding reputation. There seems to be no authoritative statement on the comparative value of these remedies, and individual drugs have been praised without controlled clinical observations. The urge for trying new remedies in hyperpiesia is prompted by the common incidence of a condition which produces bizarre symptoms and determines many complications. Although for this reason treatment is a matter of great concern, it is not likely to be very successful while the cause remains unknown.

This paper deals primarily with the effects of certain drugs on the blood pressure in patients with hyperpiesia, and also records our observations on the influence of changes in the blood pressure on the subjective symptoms. We are not concerned here with the advisability of reducing blood pressure in hyperpiesia, but our findings during short periods of a lowered pressure have convinced us that the presence of symptoms has little or no relation to the level of the blood pressure. The opportunity, however, of observing the results of a greatly lowered blood pressure in hyperpiesia over a long period has only been gained through the onset of cardiac infarction or heart failure, when the appearance of newer symptoms might mask the direct effects of the lowered pressure.

\section{METHOD OF OBSERVATION}

We submitted the following preparations to clinical trial : sodium nitrite, glyceryl trinitrate, erythrol tetranitrate, mannitol hexanitrate, bismuth subnitrate, potassium iodide, iodine, potassium bromide, sodium luminal, chloral hydrate, papaverine sulphate, euphyllin, diuretin, theominal, doryl, pacyl, hypotan, calcium chloride, atropine, potassium thiocyanate, benzyl benzoate, guipsine, detensyl, phyllosan, citrin, yohimbine hydrochloride, padutin, vagotonine, angioxyl, bioglan $\mathrm{H}$, anabolin, perandren, and œstrone. We selected these remedies either on account of a reputation which they already held in the treatment of hyperpiesia or on account of their pharmacological action in producing a fall in blood pressure. Many of the proprietary preparations were 
enlisted for trial not with any faith in their reputed hypotensive qualities but for the purpose of comparing their effects with those of the active drugs. In this way we added to our controls.

The preparations were tried in 70 patients, 13 of whom were males and 57 females. The ages varied from 38 to 72 years and the average age was 58 . Before admission into the series each patient was judged to be a case of hyperpiesia after a routine clinical examination which included urine analysis, tests of renal function, retinoscopy, electrocardiography, and radiocardioscopy. On radiocardioscopy, left ventricular enlargement and distortion of the aorta in the form of an unfolding were sought, and when either change preponderated it was noted. Any patient whose systolic blood pressure was less than $160 \mathrm{~mm}$. $\mathrm{Hg}$ or whose diastolic blood pressure was less than $100 \mathrm{~mm}$. was excluded from the series. Again, patients in whom a blood pressure of $160 / 100$ was recorded at the first examination were not admitted unless they showed a rise above this at one of two other observations. Any patient with a systolic pressure of $200 \mathrm{~mm}$. or over was not excluded simply because the diastolic pressure was less than $100 \mathrm{~mm}$. No patient with evidence of nephritis was admitted. Any who failed to co-operate during the course of the investigation was rejected.

Each patient attended the London Hospital at fortnightly intervals, but whenever a drug required parenteral administration or closer observation of its effects he was admitted into hospital. At each attendance a resting period of half an hour or longer was assured before starting observations. Questions were then asked about progress during the trial period, any change in symptoms, the occurrence of untoward or toxic manifestations, and any variation in the patient's activity or habits which might influence the course of progress. The blood pressure was then taken (to the nearest multiple of $5 \mathrm{~mm}$.) under conditions which were constant and standard for each patient. The investigation lasted for eighteen months, and over a thousand blood pressure readings were recorded, representing a similar number of observation periods each of a fortnight's duration. We came to place greater reliance on frequent controlled readings of the blood pressure in a limited number of co-operative patients, and so avoided retaining too many in the series.

The drugs were always given in adequate and usually in optimum doses, and this ensured that each patient was under the full influence of the drug soon after the start of the trial period. Although the daily dosage is instanced under each drug, it is to be understood that this was dispensed as three separate doses during the day. If symptoms of intolerance appeared it was discontinued, but was often given another trial after a suitable lapse of time. Although a single trial period usually permitted an opinion on the efficiency of a drug in reducing the blood pressure value, it was as a rule tried over several consecutive periods in a certain number of patients.

Before a remedy was judged to have established a claim to be of value as a hypotensive agent, it had to satisfy certain standards of efficiency. First, it had to be capable of reducing the blood pressure when this was raised and of maintaining it at the lower value. Secondly, it had to demonstrate this action 
consistently and in a high proportion of patients, thus proving an effect distinct from the lowered pressure which occurs as a natural periodic variation in a patient with hyperpiesia without treatment. Thirdly, this reduction had to be obtained without any toxic symptoms.

It therefore became necessary to know the extent to which the blood pressure fluctuated naturally apart from the influence of any active drug. In a series of 650 school children of the ages of 10 to 17 years Lord Dawson (1925) found among 52 in whom the systolic pressure exceeded $130 \mathrm{~mm}$. that this higher reading only remained consistently high in 17 per cent., while in the remaining 83 per cent. it was inconstant. To gain a knowledge of this natural variation in our patients we made use of frequent test periods when the patient was taking a simple placebo mixture, interspersed among test periods allotted to active drugs. The result of one such observation is charted in Fig. 1. Again, many

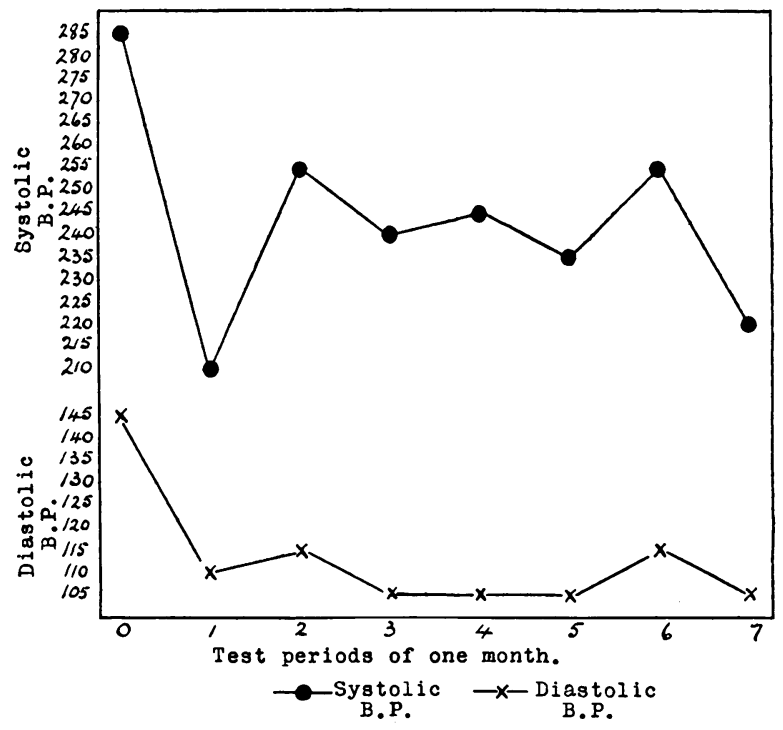

FIG. 1.-Blood pressure in a female, aged 58, with hyperpiesia, during a period of seven months when a placebo mixture was the only treatment given.

patients with hyperpiesia were observed throughout when taking only placebo mixtures, while some of those with obesity were observed during dietetic treatment and without medicine. In this way we feel that our evaluation of drugs used in the treatment of hyperpiesia, based as it is on strictly controlled observations, is substantially accurate. The second part of Fig. 2 illustrates the scheme of our observations during successive test periods of 14 days on the different drugs ; the first part showing the effect of a reducing diet (see later).

\section{RESULTS}

If the blood pressure did not rise or fall at the end of a test period by more than $10 \mathrm{~mm}$., we regarded it as showing no change. If the blood pressure fell 


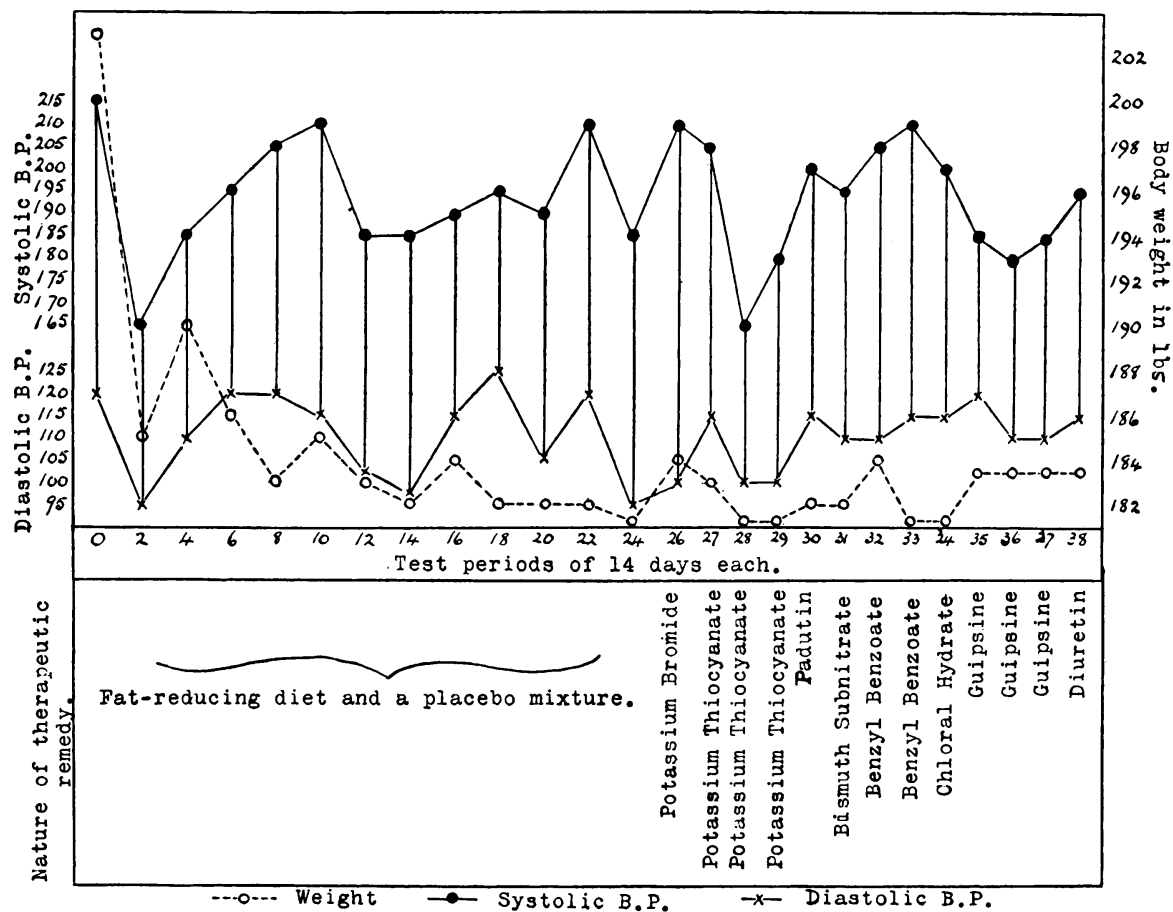

Fig. 2.-Blood pressure in a male, aged 57, with hyperpiesia, during treatment with a fatreducing diet and later with certain active drugs.

by $10 \mathrm{~mm}$. during successive observation periods, when statistically it would continue to be regarded as showing no change, we recorded it as showing a fall in the second instance. If a rise or fall of 11 to $25 \mathrm{~mm}$. occurred, we have classified it as a moderate; and if of $26 \mathrm{~mm}$. or over, as a conspicuous change. These figures apply to the systolic pressure, because we found that it was the more dependable figure upon which to judge the variation. The diastolic figure usually showed the same kind of change as the systolic, but not to the same extent, while its exact estimation could not be determined as readily as the systolic. If perchance a prominent change in the diastolic value was not also shown in the systolic value, we were careful to record it.

\section{NitRITES}

The effects of sodium nitrite on the blood pressure in healthy subjects and in patients with hyperpiesia were observed by Weiss and Ellis (1933); a fall usually occurred within 5 to 15 minutes after 1 to 5 grains had been taken by mouth, and averaged $12 \mathrm{~mm}$. for 30 minutes in the healthy subjects and $35 \mathrm{~mm}$. for two hours in the patients with hypertension.

A transient fall in the blood pressure follows the administration of amyl nitrite. Zeiss and Brams (1930) observed the action of amyl nitrite and glyceryl trinitrate on the blood pressure in 10 patients with hyperpiesia and in 10 healthy subjects. Amyl nitrite produced a fall in each of these cases, and glyceryl 
trinitrate (1/50 grain by mouth) reduced it temporarily in the healthy subjects but not always in the patients with hyperpiesia. The effects of the two drugs were also noted by Burgess (1931) ; amyl nitrite reduced the blood pressure in both groups, but glyceryl trinitrate, in doses of $1 / 100$ to $1 / 50$ grain by mouth or 1/200 grain subcutaneously, did not produce a constant effect.

In successive papers Stieglitz $(1927,1928,1930$, and 1932) has extolled the value of bismuth subnitrate as a vasodilator and as a hypotensive agent in patients with hyperpiesia. He postulated that the beneficial effect depended on the gradual vasodilatation resulting from the continuous absorption of small quantities of nitrite ions and a reduction of the blood chloride which follows the diuretic action of the nitrate ion. Ayman (1932) tried bismuth subnitrate in daily doses of 30 grains for periods of three to nine months in 15 patients with hyperpiesia ; his observations were carefully controlled and he concluded that the drug had not lowered the blood pressure in a single case. Bruen (1932) observed the hypotensive action of bismuth subnitrate in healthy subjects, and in 1934 was able to report on such a trial in a series of patients with hyperpiesia. The observations were carefully controlled, so that periods on lactose tablets and oxalate powders were compared with periods on 30,60 , and 90 grains of bismuth subnitrate daily. He concluded that bismuth subnitrate was without influence on either the blood pressure or the symptoms.

Amyl Nitrite.-We observed the effect on the blood pressure of inhalation of amyl nitrite ( 5 minims) in 22 patients with hyperpiesia and in 18 healthy subjects. There was a fall in both systolic and diastolic pressure in each of the 40 cases, but the change was more noticeable in the former. In the patients with hyperpiesia the systolic fall varied from 10 to $100 \mathrm{~mm}$., and averaged $45 \mathrm{~mm}$. The average time before the fall took place was one minute and its average duration was three minutes. A compensatory rise of an average of $22 \mathrm{~mm}$. only followed in four instances (Fig. 7). In the healthy subjects the systolic fall varied from 10 to $60 \mathrm{~mm}$. and averaged $33 \mathrm{~mm}$. The average time before the fall took place was one minute and its average duration was six minutes. A compensatory rise of an average of $36 \mathrm{~mm}$. followed in four instances.

Glyceryl Trinitrate.-We also observed the effects on the blood pressure when this was chewed in tablets containing $1 / 100,1 / 50,1 / 25$, and $1 / 12$ grain, in 7 patients with hyperpiesia and in 5 healthy subjects. A fall in both systolic and diastolic pressure occurred in each of the 12 cases. The systolic fall was the more noticeable, and in the hypertensive group varied from 25 to $195 \mathrm{~mm}$. with an average of $55 \mathrm{~mm}$. The average time before the fall took place was 6 minutes and its average duration was 16 minutes. In the healthy subjects the fall varied from 15 to $40 \mathrm{~mm}$. with an average of $26 \mathrm{~mm}$. The average time before the fall took place was 4 minutes and its average duration 16 minutes. A compensatory rise of the blood pressure value was not seen in either group.

Inhalation of amyl nitrite and the chewing of glyceryl trinitrate will therefore always cause the systolic blood pressure to fall, both in normals and in patients with hyperpiesia, the extent of the fall being greater in the latter. The fall produced with glyceryl trinitrate appears later than with amyl nitrite, but the effect lasts longer. The transient changes indicate that amyl nitrite and glyceryl 
trinitrate are unlikely to prove of value in the continuous treatment of hyperpiesia.

Sodium nitrite was submitted to a controlled clinical trial in 19 patients with hyperpiesia, and its effect observed in a daily dosage of 15 grains $(0.9 \mathrm{~g}$. during 22 test periods.* A moderate fall occurred during 2 test periods, but it did not persist when the drug was continued. There was no change during 6 , and a moderate rise took place during 6 test periods ; in 8 the effect could not be recorded as the patients failed to continue taking the drug.

Symptomatic improvement was recorded during 3 test periods on sodium nitrite, but during 19 the symptoms either remained stationary or became aggravated. Toxic effects, namely giddiness, palpitation, headache, and weakness occurred in 13, and in 8 the symptoms compelled the patients to discontinue its use.

Glyceryl trinitrate was tried in 11 patients with hyperpiesia, and its effect observed in a daily dosage of $1 / 33$ grain $(0.0018 \mathrm{~g}$.) given by mouth during 11 test periods. A fall occurred during 2 test periods, conspicuous in one and moderate in the other. There was no change during 1 , and a rise took place during 4 , conspicuous in 1 and moderate in 3 . The effects could not be recorded in 4 instances as the patients failed to take the tablets because of faintness, giddiness or palpitation.

Symptomatic improvement was recorded during 1 test period on glyceryl trinitrate, but during 10 the symptoms either remained stationary or became aggravated.

Erythrol tetranitrate was tried in 13 patients with hyperpiesia, and its effect observed in a daily dosage of $1 \frac{1}{2}$ grains $(0.09 \mathrm{~g}$.) during 19 test periods. A fall occurred during 7 , conspicuous in 5 and moderate in 2 ; there was no change during 6 ; and a rise took place during 6 , conspicuous in 1 and moderate in 5 .

Symptomatic improvement was recorded during 6 test periods on erythrol tetranitrate, but during 13 the symptoms either remained stationary or became aggravated. Toxic effects, namely giddiness and headache, occurred twice.

Mannitol hexanitrate was tried in 24 patients with hyperpiesia, and its effect observed in a daily dosage of 6 grains $(0.36 \mathrm{~g}$.) during 29 test periods. A fall occurred during 8 , conspicuous in 4 and moderate in 4 ; there was no change during 5 ; and a rise took place during 9 , conspicuous in 1 and moderate in 8 . In 7 it was not possible to record its effects because the patients failed to continue taking the drug on account of dizziness and headache.

Symptomatic improvement was recorded during 6 test periods on mannitol hexanitrate, but during 23 the symptoms either remained stationary or became aggravated.

Bismuth subnitrate was tried in 22 patients with hyperpiesia, and its effect observed in a daily dosage of 60 grains $(3.6$ g.) during 39 test periods. A fall occurred during 8 , conspicuous in 3 and moderate in 5 ; there was no change during 17 ; and a rise took place during 14, conspicuous in 5 and moderate in 9.

Symptomatic improvement was recorded during 24 test periods on bismuth

* A test period means in each case a period of 14 days. 
subnitrate, but during 15 the symptoms either remained stationary or became aggravated. Toxic effects were not seen.

$\dot{A}$ comparison of these results with those obtained from placebo treatment is made in Table $I$.

TABLE I

Comparing the Effects of Nitrites and Placebo on the Blood Pressure and on the Symptoms in Patients with Hyper piesia

\begin{tabular}{|c|c|c|c|c|c|c|}
\hline \multirow{2}{*}{ Drug } & \multirow{2}{*}{$\begin{array}{c}\text { Number } \\
\text { of Test } \\
\text { Periods }\end{array}$} & \multicolumn{3}{|c|}{ Change in Blood Pressure Value } & \multicolumn{2}{|c|}{ Effect on Symptoms } \\
\hline & & Fall & $\begin{array}{c}\text { No } \\
\text { Change }\end{array}$ & Rise & Improved & $\begin{array}{l}\text { Not } \\
\text { improved } \\
\text { or worse }\end{array}$ \\
\hline $\begin{array}{l}\text { Sodium nitrite } \\
\text { Glyceryl trinitrate ... } \\
\text { Erythrol tetranitrate } \\
\text { Mannitol hexanitrate } \\
\text { Bismuth subnitrate }\end{array}$ & $\begin{array}{l}22(60) \\
11(27) \\
19(38) \\
29(59) \\
39(40)\end{array}$ & $\begin{array}{l}14(30) \\
28(37) \\
36(42) \\
36(34) \\
20(30)\end{array}$ & $\begin{array}{l}43(57) \\
15(48) \\
32(39) \\
23(55) \\
44(65)\end{array}$ & $\begin{array}{l}43(13) \\
57(15) \\
32(19) \\
41(11) \\
36(5)\end{array}$ & $\begin{array}{l}14(33) \\
10(40) \\
32(37) \\
20(36) \\
61(33)\end{array}$ & $\begin{array}{l}86(67) \\
90(60) \\
68(63) \\
80(64) \\
39(67)\end{array}$ \\
\hline
\end{tabular}

Figures, excepting those in the first column, denote percentage of test periods. Figures in brackets apply to the placebo mixture.

\section{IODINE}

Potassium iodide intravenously often causes the blood pressure to fall, but Macht (1914) showed that its hypotensive effect was due to potassium and not the iodine ion. Mosenthal (1933) obtained hypotensive effects from the use of sodium and potassium iodide in daily doses of 3 to 10 grains in cases of hypertension. The use of iodine in hyperpiesia is also mentioned by others (Norris, Bazett, and McMillan, 1927 ; Gager, 1930 ; Hay, 1931 ; Parkinson, 1936 ; White, 1937). Livingstone (1935) advocated the use of Lugol's iodine. Lewis (1937), speaking on drugs used in hyperpiesia, said that none offered much prospect of benefit and that even potassium iodide, which had long been favoured as a remedy, was losing its reputation in this field.

Iodine, as Lugol's solution, was tried in 20 patients with hyperpiesia, and its effect observed in a daily dosage of 18 minims $(1 \cdot 1$ c.c.) during 42 test periods. A moderate fall occurred during 5 test periods ; there was no change during 28 ; and a rise during 9 , conspicuous once and moderate in 8 .

Symptomatic improvement was recorded during 18 test periods on iodine, but during 24 the symptoms either remained stationary or became aggravated.

Potassium iodide was submitted to a controlled clinical trial in 23 patients with hyperpiesia, and its effect observed in a daily dosage of 30 grains $(1 \cdot 8 \mathrm{~g}$.) during 28 test periods. A fall occurred during 4 test periods, conspicuous in 1 and moderate in 3 ; there was no change during 19 ; and a rise took place during 5 , conspicuous in 4 and moderate once.

Symptomatic improvement was recorded during 10 test periods on potassium iodide, but during 18 the symptoms either remained stationary or became aggravated. 
A comparison of these results with those obtained from placebo treatment is made in Table II.

TABLE II

Comparing the Effects of Iodine and Placebo on the Blood Pressure and on THE Symptoms in PATIENTS With HyPerpiesia

\begin{tabular}{|c|c|c|c|c|c|c|}
\hline \multirow{2}{*}{ Drug } & \multirow{2}{*}{$\begin{array}{c}\text { Number } \\
\text { of Test } \\
\text { Periods }\end{array}$} & \multicolumn{3}{|c|}{ Change in Blood Pressure Value } & \multicolumn{2}{|c|}{ Effect on Symptoms } \\
\hline & & Fall & $\begin{array}{c}\text { No } \\
\text { Change }\end{array}$ & Rise & Improved & $\begin{array}{c}\text { Not } \\
\text { improved } \\
\text { or worse }\end{array}$ \\
\hline Iodine & $42(53)$ & $10(26)$ & $67(57)$ & $23(17)$ & $43(30)$ & $57(70)$ \\
\hline Potassium iodide & $28(53)$ & $14(29)$ & $68(48)$ & $18(23)$ & $36(30)$ & $64(70)$ \\
\hline
\end{tabular}

Figures, excepting those in the first column, denote percentage of test periods. Figures in brackets apply to placebo.

\section{SEDATIVES}

Bromide.-We have not found reports of any observations on the effects of bromide on the blood pressure in hyperpiesia, but its use has been mentioned especially in connection with the relief of symptoms (Gager, 1930 ; Hay, 1931 ; Parkinson, 1936 ; White, 1937).

Potassium bromide was tried in 40 patients with hyperpiesia, and its effect observed in a daily dosage of 30 grains $(1.8 \mathrm{~g}$.) during 66 test periods. A fall occurred during 21 , conspicuous in 8 and moderate in 13 ; there was no change during 29 ; and a rise took place during 16, conspicuous in 6 and moderate in 10.

Symptomatic improvement was recorded during 27 test periods on potassium bromide, but during 39 the symptoms either remained stationary or became aggravated.

Sodium Luminal.-Gruber and others (1925) gave luminal in daily doses of $4 \frac{1}{2}$ grains to 36 patients with hypertension, and found a fall in pressure in 85 per cent., but the degree of this fall is not given, and it was not maintained on prolonged administration. Hay (1931) attributed to luminal a slight hypotensive as well as sedative effect, but this action was evanescent and was more likely to prove beneficial in early cases. Parkinson (1936) favoured luminal along with bromide in relieving symptoms, particularly palpitation and restlessness. Adson and Allen (1937) regarded sedatives, especially the barbiturates, as the most valuable drugs in high blood pressure, and stated that under controlled conditions it fell to normal in many patients, and that the dosage should be adjusted to secure a sedative action without causing drowsiness.

We submitted sodium luminal to trial in 38 patients with hyperpiesia, and observed its effect in a daily dosage of $1 \frac{1}{2}$ grains $(0.09 \mathrm{~g}$.) during 52 test periods. A fall occurred during 14, conspicuous in 5 and moderate in 9 ; there was no change during 26 ; and a rise took place during 12, conspicuous in 2 and moderate in 10 . 
Symptomatic improvement was recorded during 21 test periods on sodium luminal, but during 31 the symptoms either remained stationary or became aggravated. Toxic effects were not seen.

Chloral Hydrate.-Matte and Dias-Cavaroni (1926) reported on an investigation of the effects of certain drugs on the blood pressure in cases of hyperpiesia. They found that chloral hydrate frequently reduced the systolic pressure, but that this effect seldom lasted more than ten days.

We submitted chloral hydrate to a trial in 23 patients with hyperpiesia, and observed its effect in a daily dosage of 30 grains $(1 \cdot 8 \mathrm{~g}$.) during 33 test periods. A fall occurred during 10 test periods, conspicuous in 4 and moderate in 6 ; there was no change during 17 ; and a rise took place during 5 , conspicuous in 2 and moderate in 3 . In one instance the effect could not be recorded, because of dizziness and headache.

Symptomatic improvement was recorded during 7 test periods on chloral hydrate, but during 26 the symptoms either remained stationary or became aggravated.

Papaverine Sulphate.-Reporting on an experimental study of papaverine sulphate, Macht (1916) stated that it slowed the heart rate and reduced the blood pressure through vasodilatation of the peripheral arteries. The use of opium was mentioned by Norris, Bazett, and McMillan (1927), and White (1937) mentioned papaverine in the treatment of hyperpiesia, but expressed no opinion as to its value.

We submitted papaverine sulphate to a trial in 16 patients with hyperpiesia, and observed its effect in a daily dosage of $7 \frac{1}{2}$ grains $(0.45 \mathrm{~g}$.) during 24 test periods. A fall occurred during 8 , conspicuous in 4 and moderate in 4 ; there was no change during 13 ; and a moderate rise took place during 3.

Symptomatic improvement was recorded during 6 test periods on papaverine sulphate, but during 18 the symptoms either remained stationary or became aggravated. Toxic effects were not seen.

A comparison of these results with those obtained from placebo treatment is made in Table III.

TABLE III

Comparing the Effects of Sedative Drugs and Placebo on the Blood Pressure and on the Symptoms in Patients With Hyperpiesia

\begin{tabular}{|c|c|c|c|c|c|c|}
\hline \multirow{2}{*}{ Drug } & \multirow{2}{*}{$\begin{array}{l}\text { Number } \\
\text { of Test } \\
\text { Periods }\end{array}$} & \multicolumn{3}{|c|}{ Change in Blood Pressure } & \multicolumn{2}{|c|}{ Effect on Symptoms } \\
\hline & & Fall & $\begin{array}{c}\text { No } \\
\text { Change }\end{array}$ & Rise & Improved & $\begin{array}{l}\text { Not } \\
\text { improved } \\
\text { or worse }\end{array}$ \\
\hline $\begin{array}{l}\text { Potassium bromide } \\
\text { Sodium luminal } \\
\text { Chloral hydrate } \\
\text { Papaverine sulphate }\end{array}$ & $\begin{array}{l}66(90) \\
52(90) \\
33(43) \\
24(31)\end{array}$ & $\begin{array}{l}32(31) \\
27(31) \\
30(29) \\
34(42)\end{array}$ & $\begin{array}{l}44(52) \\
50(51) \\
55(56) \\
54(46)\end{array}$ & $\begin{array}{l}24(17) \\
23(18) \\
15(15) \\
12(12)\end{array}$ & $\begin{array}{l}41(34) \\
40(30) \\
20(30) \\
25(32)\end{array}$ & $\begin{array}{l}59(66) \\
60(70) \\
80(70) \\
75(68)\end{array}$ \\
\hline
\end{tabular}

Figures, excepting those in the first column, denote percentage of test periods. Figures in brackets apply to placebo. 


\section{Xanthine Derivatives}

The xanthine derivatives have been mentioned in connection with the treatment of hyperpiesia by Livingstone (1935), White (1937), and Lewis (1937), but without an opinion on their actual value as hypotensive agents. Calcium diuretin, in the experience of Basch (1924), caused the blood pressure in hypertension to fall at times as much as $40 \mathrm{~mm}$. and to remain at the lowered figure ; and Kaiser (1925) also obtained good results from it.

We submitted euphyllin (theophylline-ethylene-diamine) to a trial in 31 patients with hyperpiesia, and observed its effect in a daily dosage of 9 grains ( 0.6 g.) during 41 test periods. A fall occurred during 11 test periods, conspicuous in 4 and moderate in 7 ; there was no change during 23 ; and a rise took place during 7, conspicuous in 2 and moderate in 5 .

Symptomatic improvement was recorded during 10 test periods on euphyllin, but during 31 the symptoms either remained stationary or became aggravated. Toxic effects, namely weakness, insomnia, headache, and palpitation occurred twice.

We submitted diuretin (theobromine-sodio-salicylate) to a trial in 26 patients with hyperpiesia, and observed its effect in a daily dosage of either 30 grains ( 1.8 g.) or 45 grains $(2 \cdot 7$ g.) during 30 test periods. A fall occurred during 5 test periods, conspicuous in 1 and moderate in 4 ; there was no change during 16 ; and a rise took place during 4 test periods, conspicuous in 1 and moderate in 3 . In 5 instances the effects could not be recorded because the patients failed to continue taking the drug on account of giddiness, headache and sickness. These symptoms were also present in three others and were more noticeable with the larger dose.

Symptomatic improvement was recorded during 4 test periods on diuretin, but during 26 the symptoms either remained stationary or became aggravated.

A comparison of the results of these drugs and theominal with those obtained from placebo treatment is made in Table IV.

TABLE IV

Comparing the Effects of Drugs belonging to the Xanthine Group and Placebo on the Blood Pressure and on the Symptoms in Patients With Hyperpiesia

\begin{tabular}{|c|c|c|c|c|c|c|c|}
\hline \multirow{2}{*}{ Drug } & & \multirow{2}{*}{$\begin{array}{l}\text { Number } \\
\text { of Test } \\
\text { Periods }\end{array}$} & \multicolumn{3}{|c|}{ Change in Blood Pressure Value } & \multicolumn{2}{|c|}{ Effect on Symptoms } \\
\hline & & & Fall & $\begin{array}{c}\text { No } \\
\text { Change }\end{array}$ & Rise & Improved & $\begin{array}{l}\text { Not } \\
\text { improved } \\
\text { or worse }\end{array}$ \\
\hline $\begin{array}{ll}\text { Euphyllin } & \ldots \\
\text { Diuretin } & \text {. } \\
\text { Theominal } & \text {.. }\end{array}$ & $\begin{array}{l}\ldots \\
\cdots \\
\ldots\end{array}$ & $\begin{array}{l}41(81) \\
30(64) \\
21(48)\end{array}$ & $\begin{array}{l}27(31) \\
20(30) \\
23(40)\end{array}$ & $\begin{array}{l}56(54) \\
64(57) \\
53(44)\end{array}$ & $\begin{array}{l}17(15) \\
16(13) \\
24(16)\end{array}$ & $\begin{array}{l}24(33) \\
13(33) \\
33(31)\end{array}$ & $\begin{array}{l}76(67) \\
87(67) \\
67(69)\end{array}$ \\
\hline
\end{tabular}

Figures, excepting those in the first column, denote percentage of test periods. Figures in brackets apply to placebo.

We submitted theominal (sodium luminal and theobromine) to a trial in 16 patients with hyperpiesia, and observed its effect in a daily dosage of 30 grains 
( $1.8 \mathrm{~g}$.) during 21 test periods. A moderate fall occurred during 4 test periods ; there was no change during 9 ; and a rise took place during 4 , conspicuous in one and moderate in 3.

Symptomatic improvement was recorded during 7 test periods on theominal, but during 14 the symptoms either remained stationary or became aggravated. Toxic effects, namely giddiness or drowsiness, occurred four times, and compelled the patients to discontinue its use.

\section{Choline Derivatives}

Acetylcholine.-A fall in blood pressure as a result of vasodilatation was shown in the cat by Dale (1914) after small doses of this intravenously. Wolff (1929) was also able to show vasodilatation in organs supplied by the parasympathetic nervous system and a generalized dilatation of the cutaneous arterioles. Meakins and Scriven (1931) recorded a fall of from 25 to $40 \mathrm{~mm}$. in 72 per cent. of their observations on seven cases of hypertension following intramuscular injections of $0 \cdot 1$ to $0.2 \mathrm{~g}$. of acetylcholine; the effect lasted from one to four hours. Only three out of thirteen healthy subjects showed an appreciable fall in blood pressure after intravascular administration of 2 per cent. acetylcholine given at the rate of 0.02 to $0.14 \mathrm{~g}$. per minute (Ellis and Weiss, 1932). Carmichael and Fraser (1933) gave it intravenously in doses of from 0.01 to $0.03 \mathrm{~g}$. to 46 subjects, and cardio-inhibitory effects appeared within five to ten seconds, but lasted only a few seconds. The slowing of the heart rate was followed by an acceleration, and the systolic and diastolic pressure fell during the phase of slow heart rate, but returned to normal or even higher during the phase of increased heart rate. More recently Fraser (1938) stated that the administration of acetylcholine in man gave disappointing therapeutic results; when given intravascularly the effects are too brief, and when given intramuscularly too uncertain.

Doryl (carbaminoyl-choline) and Mecholin (acetyl- $\beta$-methyl-choline) are more stable than acetylcholine and are active even when given by mouth. Their hypotensive properties have been demonstrated by Kreitmair (1932), Dautrebande (1933) and Fraser (1938), but Fraser has pointed out that both preparations are valueless in the treatment of hyperpiesia, except for the relief of hypertensive headache. Pacyl is another choline derivative which is said to be active when given by mouth. Lewy (1928) and Ganter (1928) reported hypotensive effects and symptomatic improvement from its use. The preparation hypotan is a mixture of methylacetylcholine, bromocholine bromide and chloral hydrate. Its use in hypertension has been recommended on account of its alleged action as a vasodilator.

We submitted doryl to a controlled clinical trial in 11 patients with hyperpiesia, and observed its effect in a daily dosage of 6 tablets during 12 test periods. A temporary moderate fall occurred during 1 test period ; there was no change during 4 ; and a rise took place during 3 test periods, conspicuous in 2 and moderate in 1 . The effect could not be recorded in 4 instances because the patients failed to continue taking the preparation. 
Symptomatic improvement was recorded during 3 test periods on doryl, but during 9 the symptoms either remained stationary or became aggravated. Toxic effects, namely sweating, weakness, giddiness and nausea, occurred in 5 instances.

Pacyl was tried in 11 patients with hyperpiesia, and its effect on the blood pressure in a daily dosage of 6 tablets observed during 22 test periods. A fall occurred during 4, conspicuous in 2 and moderate in 2 ; there was no change during 15 ; and a rise took place during 3 , conspicuous in 1 and moderate in 2 .

Symptomatic improvement was recorded during 10 test periods on pacyl, but during 12 the symptoms either remained stationary or became aggravated.

Hypotan was tried in 19 patients with hyperpiesia, and its effect observed in a daily dosage of 8 tablets during 36 test periods. A fall occurred during 10, conspicuous in 3 and moderate in 7 ; there was no change during 16 ; and a rise took place during 10, conspicuous in 5 and moderate in 5 .

Symptomatic improvement was recorded during 14 test periods on hypotan, but during 22 the symptoms either remained stationary or became aggravated.

A comparison of these results with those obtained from placebo treatment is made in Table $\mathrm{V}$.

\section{TABLE V}

Comparing the Effects of Acetylcholine Derivatives and Placebo on the Blood Pressure and on the Symptoms in Patients With Hyperpiesia

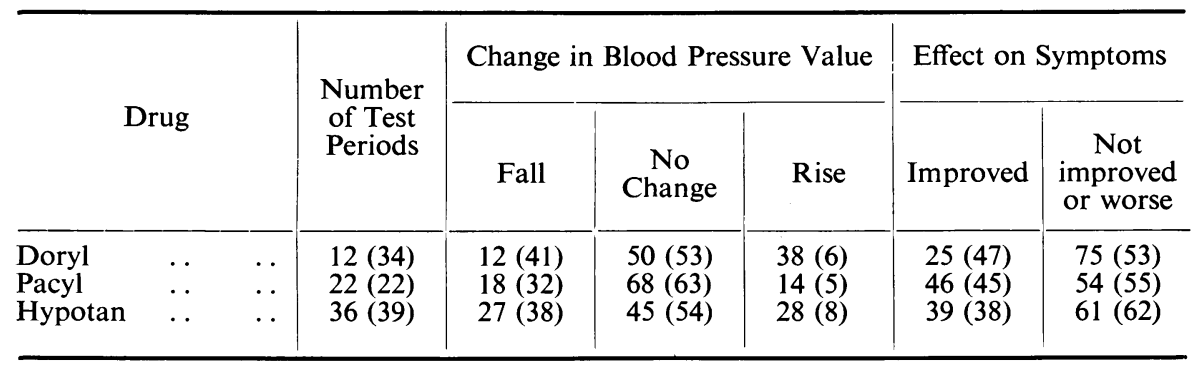

Figures, excepting those in the first column, denote percentage of test periods. Figures in brackets apply to placebo.

\section{Other Chemical Drugs}

Calcium Chloride.-The neutralizing action of calcium and potassium chloride on the pressor substances of the guanidine series was mentioned by Major (1925). Addison and Clark (1925) treated 45 patients with hypertension with calcium chloride in daily doses of 90 to 180 grains, and found a persistent fall of $30 \mathrm{~mm}$. or more in the systolic pressure and of $12 \mathrm{~mm}$. or more in the diastolic pressure in 26 cases. Altnow and O'Hare (1927) used calcium chloride and atropine in the treatment of 11 cases with hypertension ; no fall in pressure was noticed in 6 and it was insignificant in the remaining 5 patients.

Calcium chloride was tried in 20 patients with hyperpiesia, and its effect observed in a daily dosage of 90 grains $(6$ g.) during 25 test periods. A fall 
occurred during 4, conspicuous in 1 and moderate in 3 ; there was no change during 11 ; and a rise took place during 6, conspicuous in 2 and moderate in 4. In 4 other instances it was not possible to record the effects because of a burning taste in the mouth, sickness or epigastric pain.

Symptomatic improvement was recorded during 6 test periods on calcium chloride, but during 19 the symptoms either remained stationary or became aggravated.

Atropine.-This has been recommended for hypertension on the assumption that raised blood pressure is the outcome of an unbalanced action in the autonomic system, so that the vagal action preponderates over the sympathetic. Altnow and O'Hare (1927) treated 11 patients with calcium chloride and atropine, but without any change in 6 and with an insignificant change in the remaining 5. Norris, Bazett, and McMillan (1927) stated that experimentally atropine raises the blood pressure through stimulation of the vasoconstrictor centre and raising the pulse rate, but that this pressor effect was rarely met with clinically. White (1937) also mentioned the use of atropine in hypertension.

We submitted atropine sulphate to a trial in 9 patients with hyperpiesia, and observed its effect in a daily oral dosage of $1 / 20$ grain $(0.003 \mathrm{~g}$.) during 9 test periods. A moderate fall occurred during 1 test period ; there was no change during 5 ; and a rise took place during 2, conspicuous in 1 and moderate in another. In one instance it was not possible to record the effects because of dryness of the mouth and mistiness of vision, and these symptoms were also present in 6 others who persisted with the drug.

Symptomatic improvement was recorded during 3 test periods on atropine sulphate, but during 6 the symptoms either remained stationary or became aggravated.

Potassium Thiocyanate (potassium rhodanate).-During a clinical trial of the effects of cyanate in patients suffering from neurasthenia, Pauli (1903 and 1904) observed both a reduction in the pressure and an improvement of symptoms when hypertension was present. Nichols (1925) stated that the drug was excreted slowly and that cumulative effects might appear ; it was, however, excreted unchanged without the formation of the poisonous prussic acid radicle. Therapeutically he found it reduced the blood pressure to a greater extent than any other drug in hyperpiesia. Smith and Rudolf (1928) gave sodium sulphocyanate to five healthy subjects and to 72 cases with hypertension, the daily dose for one group being 5 grains, for another 10 grains and for a third 15 grains A fall in blood pressure occurred in each of the healthy subjects and each of the patients with hypertension, and the change was more noticeable in the latter. They observed a fall of as much as $100 \mathrm{~mm}$. in the systolic pressure, and as a rule the greater fall followed the greater dosage. Better results were obtained in those patients without evidence of renal damage and in those who showed the least amount of arterial changes from atheroma. No severe toxic symptoms

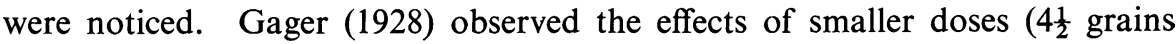
or less daily) of sulphocyanate in 25 patients with hyperpiesia. It was lowered in 22, sometimes by 20 to $60 \mathrm{~mm}$. The fall in the diastolic pressure was not as conspicuous. Subjective improvement was often recorded. Palmer, Silver, 
and White (1929) using the same dosage as Gager in 59 cases of hyperpiesia found a reduction of $30 \mathrm{~mm}$. or more in the systolic pressure in 42 per cent. Fineberg (1930), comparing the effects of thiocyanate and sedatives, found that the blood pressure was more often reduced by thiocyanate, but that greater subjective improvement followed sedatives. During controlled observations in 25 patients, Egloff, Hoyt, and O'Hare (1931) obtained a favourable response twice only. Treatment of 99 patients with hypertension with sulphocyanate in doses varying from 5 to 15 grains daily over periods up to three years resulted in a reduction of blood pressure in 68 per cent. (Bolotin, 1932). Both Palmer (1932) and Goldring and Chassis (1932) found that thiocyanate reduced the pressure in 31 per cent. of cases ; but Palmer found it did not persist and that often where it had fallen initially with treatment a retrial failed to reproduce this effect. Goldring and Chassis found toxic symptoms in 17 per cent. of their cases, and two deaths were attributed to the drug. A fall in the pressure was noted by Ayman (1931) in 20 of 31 cases with hyperpiesia, but in 19 out of the 20 it was accompanied by distressing toxic symptoms, both in large doses over short periods and in small doses over longer periods. Barker (1936 and 1937) stressed the importance of estimating the cyanate content of the blood during treatment, and thought the optimum benefit occurred when it was maintained at 8 to $12 \mathrm{mg}$. per 100 c.c.; when it reached 15 to $30 \mathrm{mg}$. toxic symptoms appeared. The standard concentration in the blood was never obtained by a constant cyanate dosage. He stated that if the concentration was maintained at a suitable level, a fall in blood pressure and symptomatic improvement would be expected in 50 per cent. of cases. When this standard concentration was maintained in 16 patients with hypertension, Griffith and Lindauer (1937) found that both the systolic and diastolic blood pressure became lowered in 10 with improvement of general symptoms and without any severe toxic effects. Massie, Ethridge, and O'Hare (1938) gave sodium thiocyanate to 14 patients with hyperpiesia, under controlled conditions, and found it reduced the pressure and improved the symptoms.

We submitted potassium thiocyanate to a trial in 38 patients with hyperpiesia, and observed its effect in a daily dosage of $4 \frac{1}{2}$ grains $(0 \cdot 3 \mathrm{~g}$.) during 90 test periods. A fall occurred during 34 , conspicuous in 11 and moderate in 23 ; there was no change during 36 ; and a rise took place during 20, conspicuous in 6 and moderate in 14.

Symptomatic improvement was recorded during 31 test periods on potassium thiocyanate, but during 59 the symptoms either remained stationary or became aggravated. Toxic effects were not seen.

Benzyl Benzoate.-Macht (1918), as the result of experiments in animals, found this diminished the tonicity of smooth muscle, and decided on a clinical trial in intestinal colic, bronchial spasm and angiospasm. Using 45 minims of a 20 per cent. alcoholic solution daily he claimed good results in 100 cases, including many with hyperpiesia. Later Macht (1920) reaffirmed his opinion on its beneficial effects and gave further examples in which a raised blood pressure had been reduced by the daily administration of from 60 to 90 minims of the 20 per cent. alcoholic solution. These observations were not con- 
trolled and the proportion responding successfully was not expressed. Laubry and Mougeot (1921) submitted benzyl benzoate to a clinical trial and concluded that it was a useful drug to combine with others because it gave results which were sometimes surprising, rarely negligible, and never harmful. Gruber and Shackelford (1924) gave 120 minims of the 20 per cent. alcoholic solution of benzyl benzoate daily for periods of four to eighteen days to 16 patients with hyperpiesia. Their observations were carefully controlled and appeared to show that when given by mouth it had no effect on the raised pressure in hyperpiesia.

We submitted benzyl benzoate to a trial in 30 patients with hyperpiesia, and observed its effect in a daily dosage of 24 minims (1.6 mils) during 45 test periods. A fall occurred during 7 test periods, conspicuous in 3 and moderate in 4 ; there was no change during 23 ; and a rise took place during 15 , conspicuous once and moderate in 14 instances.

Symptomatic improvement was recorded during 15 test periods, but during 30 the symptoms either remained stationary or became worse.

A comparison of these results with those obtained from placebo treatment is made in Table VI.

\section{TABLE VI}

Comparing the Effects of Calcium Chloride, Atropine Sulphate, Potassium Thiocyanate, and Benzyl Benzoate with those of a Placebo on the Blood Pressure AND ON THE Symptoms in Patients With Hyperpiesia

\begin{tabular}{|c|c|c|c|c|c|c|}
\hline \multirow{2}{*}{ Drug } & \multirow{2}{*}{$\begin{array}{l}\text { Number } \\
\text { of Test } \\
\text { Periods }\end{array}$} & \multicolumn{3}{|c|}{ Change in Blood Pressure Value } & \multicolumn{2}{|c|}{ Effect on Symptoms } \\
\hline & & Fall & $\begin{array}{c}\text { No } \\
\text { Change }\end{array}$ & Rise & Improved & $\begin{array}{l}\text { Not } \\
\text { improved } \\
\text { or worse }\end{array}$ \\
\hline $\begin{array}{l}\text { Calcium chloride } . . \\
\text { Atropine sulphate ... } \\
\text { Potassium thiocyanate } \\
\text { Benzyl benzoate } \quad . .\end{array}$ & $\begin{array}{r}25(43) \\
9(30) \\
90(88) \\
45(61)\end{array}$ & $\begin{array}{l}18(32) \\
12(42) \\
37(36) \\
16(39)\end{array}$ & $\begin{array}{l}54(58) \\
64(46) \\
40(50) \\
51(48)\end{array}$ & $\begin{array}{l}28(10) \\
24(12) \\
23(14) \\
33(13)\end{array}$ & $\begin{array}{l}24(37) \\
33(33) \\
34(31) \\
33(34)\end{array}$ & $\begin{array}{l}76(63) \\
67(67) \\
66(69) \\
67(66)\end{array}$ \\
\hline
\end{tabular}

Figures, excepting those in the first column, denote percentage of test periods. Figures in brackets apply to placebo.

\section{Some Vegetable Extracts}

Guipsine.-This is a preparation of mistletoe which has been advocated on account of its alleged action as a vasodilator of the peripheral arterioles.

Guipsine was tried in 12 patients with hyperpiesia, and its effect observed in a daily dosage of 9 pills during 19 test periods. A fall occurred during 6, conspicuous in 1 and moderate in 5 ; there was no change during 9 ; and a rise took place during 4, conspicuous once and moderate in 3 instances.

Symptomatic improvement was recorded during 4 test periods on guipsine, but during 15 the symptoms either remained stationary or became worse.

Detensyl.-This consists of extracts of mistletoe, liver, pancreas and lung ; and because a hypotensive action from vasodilatation has been ascribed to each of these constituents it has sometimes been recommended. 
We submitted detensyl to a trial in 14 patients with hyperpiesia, and observed its effect in a daily dosage of 4 tablets during 18 test periods. A fall occurred during 4 test periods, conspicuous in 1 and moderate in 3 ; there was no change during 9 ; and a rise took place during 4 , conspicuous in 1 and moderate in 3 . One patient failed to take the tablets.

Symptomatic improvement was recorded during 6 test periods on detensyl, but during 12 the symptoms either remained stationary or became aggravated.

Phyllosan is the name given to a concentrated extract of chlorophyll obtained from green vegetables. Originally recommended in the treatment of anæmia, it has recently been accredited with hypotensive effects, but on such meagre evidence that we accepted it into our series for additional control observations.

We submitted phyllosan to a trial in 9 patients with hyperpiesia, and observed its effect in a daily dosage of 6 tablets during 16 test periods. A moderate fall occurred during 4 ; there was no change during 9 ; and a rise took place during 2 test periods, conspicuous in one and moderate in another. The effect could not be recorded in one patient because he was unable to take this medicine on account of giddiness.

Symptomatic improvement was recorded during 5 test periods, but during 11 the symptoms either remained stationary or became worse.

Citrin (cucurbocitrin).-Barksdale (1926) isolated an active principle from the seed of the water-melon which belongs to the group of glucoside-saponins and which prove on experiment to dilate the smaller arteries. Barksdale claimed good results in 10 cases of nephritic hypertension. In 68 patients in whom the blood pressure was raised, Wilkinson (1927) found a fall with symptomatic improvement in 82 per cent. Cucurbocitrin was given by Althausen and Kerr (1929) in daily doses of 150 to $450 \mathrm{mg}$. to 40 patients with hypertension. An immediate fall in pressure was noticed and its extent appeared to be directly dependent on the dosage. After prolonged administration an average fall of $29 \mathrm{~mm}$. in the systolic and of $15 \mathrm{~mm}$. in the diastolic pressure occurred in 73 per cent. of the cases, while symptomatic improvement was recorded in even more ; toxic symptoms were never noted. Gargill and Rudy (1931) treated 29 cases of hyperpiesia with cucurbocitrin and found it of no value ; in only 7 instances was the systolic pressure reduced by $25 \mathrm{~mm}$., a reduction which might occur spontaneously. Seward (1931) prescribed it in 16 patients in doses varying from 150 to $200 \mathrm{mg}$. daily. The blood pressure was reduced in 4 after treatment for fourteen days, and this effect lasted for some time and went with symptomatic improvement. Later he (1932) reported that in 9 out of 22 cases the systolic pressure was reduced by $30 \mathrm{~mm}$. and the diastolic by $10 \mathrm{~mm}$. following treatment with citrin in doses of from 300 to $400 \mathrm{mg}$. daily.

We submitted citrin to a trial in 13 patients with hyperpiesia, and observed its effect in a daily dosage of $300 \mathrm{mg}$. during 13 test periods. A fall occurred during 2 test periods, conspicuous in 1 and moderate in 1 ; there was no change during 7 ; and a rise took place during 2 , conspicuous in 1 and moderate in 1 . In 2 instances the patients were unable to continue taking the medicine.

Symptomatic improvement was recorded during 4 test periods on citrin, but during 9 the symptoms either remained stationary or became aggravated. 
Toxic effects, namely headache, insomnia and a sense of choking, occurred in 3 instances.

Yohimbine, an alkaloid obtained from yohimbine bark, is a peripheral vasodilator, and produces a small hypotensive effect. It is said to augment the action of other agents, and Loeper and Lemaire (1930) found that in dogs previously treated with yohimbine, the hypotensive effects of acetylcholine were four times as great. Barrieu (1932) reported good results from such a combination when given to patients. Taken with phenylethyl-barbituric acid it was favoured by Busquet and Vischniac (1935).

We submitted yohimbine hydrochloride to a trial in 16 patients with hyperpiesia, and observed its effect in a daily dosage of $1 / 3$ grain $(0.02 \mathrm{~g}$.) during 18 test periods. A moderate fall occurred during 3 ; there was no change during 6 ; and a moderate rise took place during 5. In 4 instances the patients could not continue taking the drug.

Symptomatic improvement was recorded during 4 test periods on yohimbine, but during 14 the symptoms either remained stationary or became worse. Toxic effects, namely trembling, shivering, dizziness, and headache, occurred in six instances.

\section{Some Animal Extracts and Hormones}

Padutin, originally known as kallikrein, is a pancreatic extract. It is alleged to contain a vasomotor hormone with hypotensive properties when given either by mouth or by intramuscular injection, and it is standardized by physiological methods. A fall in blood pressure was observed by Leschke (1930) in patients with hyperpiesia when taking padutin. In some the fall was considerable and persistent, while in others it was slight and transient. Scharpff (1931) compared the effects on the blood pressure of rest and a restricted diet, with and without padutin. A fall in pressure occurred in both groups, but was more noticeable in those taking padutin, where the average fall in the systolic and diastolic values was 64 and $31 \mathrm{~mm}$. as against an average fall of 35 and $5 \mathrm{~mm}$. in patients not taking padutin. Subjective improvement was also recorded. Nuzum, Elliot, and Bischoff (1937) gave kallikrein hypodermically in ten patients ; they controlled their results and found a fall in pressure in only two patients while the symptoms remained unchanged. Wolffe and others (1937) observed the effects of de-insulinated pancreatic extract in 150 patients with hypertension. A fall in systolic and diastolic pressure occurred in 108, and in 8 of these it was conspicuous; symptomatic improvement was noticed in 62 per cent. and lasted for over twelve months. In the remaining 42 the changes were comparable with those observed in a control series.

We submitted padutin to a trial in 36 patients with hyperpiesia, and observed its effect in a daily dosage of 60 minims ( $3 \cdot 6$ c.c.) during 46 test periods. A fall occurred during 9 test periods, conspicuous in 5 and moderate in 4 ; there was no change during 21 ; and a rise took place during 16, conspicuous in 5 and moderate in 11 . 
Symptomatic improvement was recorded during 17 test periods on padutin, but during 29 the symptoms either remained stationary or became aggravated.

Vagotonine is obtained from the pancreas, and its specific physiological action is said to be one antagonizing the action of adrenaline and restraining its secretion ; through its action on the sympathetic system it reduces vasomotor tonicity. Abrami, Santenoise, and Bernal (1933) recorded a fall in the blood pressure in 42 of 80 cases of hypertension after subcutaneous injections of 20 or more often $40 \mathrm{mg}$. of vagotonine. If a fall did not occur within two hours of the first injection, they did not expect any reduction from daily injections even when repeated on twenty consecutive days; on the other hand, the fall which commenced within two hours was maintained from 12 to 48 hours. Urticaria was sometimes seen.

We observed the effects of a subcutaneous injection of $0.02 \mathrm{~g}$. of vagotonine in 6 patients with hyperpiesia, and in one of these the injection was repeated. Frequent blood pressure readings were taken before and after the injection for a period not less than two hours, and further readings were recorded on subsequent days. We also had evidence of the variation in the blood pressure value during periods of treatment with active drugs or placebo mixtures. In none of our 6 patients was the blood pressure lowered, either immediately or more remotely, by injections of vagotonine and indeed it was at a higher level after the injection in 4 of them. We concluded that vagotonine had no place in the treatment of hyperpiesia, for in the patients in whom it was given a trial it produced no hypotensive effects. In one patient it gave rise to very severe urticaria.

Angioxyl is an insulin-free extract of pancreas which is standardized physiologically. It has been claimed that it antagonizes the action of adrenaline and that it produces vasodilatation, resulting in a lowering of the blood pressure.

We submitted it to a trial in 10 patients with hyperpiesia, and observed its effect in a daily dosage of 80 units during 15 test periods. A fall occurred during 5 , conspicuous in 3 and moderate in 2 ; there was no change during 5 ; and a rise took place during 4, conspicuous in 2 and moderate in 2 . In one instance the patient had failed to take the medicine on account of headache.

Symptomatic improvement was recorded during 5 test periods on angioxyl, but during 10 the symptoms either remained stationary or became aggravated.

Bioglan $H$ consists of a concentration of hormones obtained from pancreas, anterior pituitary and human placenta. In 20 cases of hypertension selected from the druggist's laboratory files it is recorded that an average blood pressure of 210/117 before treatment became 158/91 after treatment, and this reduced value had persisted for a year after the initial course of injections.

One c.c. of bioglan $\mathrm{H}$ was injected intramuscularly twice weekly for three weeks in four female patients with hyperpiesia, and for two weeks in a male patient. Daily blood pressure readings were taken under controlled conditions and when these were considered it was found that in no instance had it caused any reduction.

A comparison of the results of these preparations and of anabolin with those obtained from placebo treatment is made in Table VII. 
TABLE VII

Comparing the Effects of 8 Preparations with those of a Placebo on the Blood Pressure and on the Symptoms in Patients with Hyperpiesia

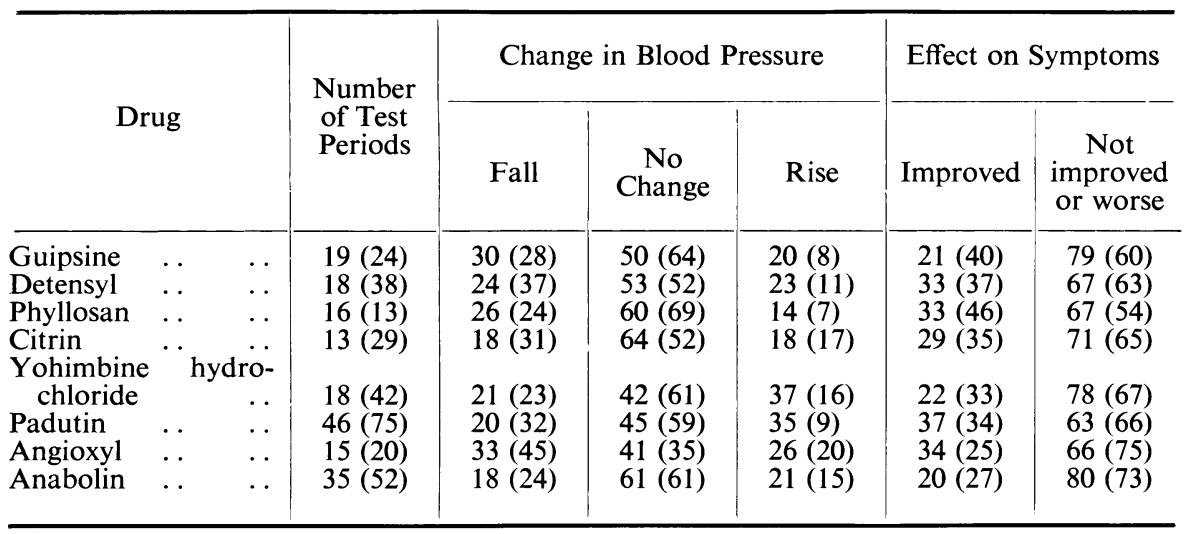

Figures, excepting those in the first column, denote percentage of test periods. Figures in brackets apply to placebo.

Anabolin is an extract of liver isolated by alcohol fractionation methods, and its introduction into clinical medicine in the treatment of hyperpiesia has depended on its specific action as a vasodilator. Its pharmacological action in lowering blood pressure in the experimental animal is constant and uniform, so that solutions containing it can be standardized by this method. Major (1924 and 1925) appeared to show that hypertension could be induced experimentally by the introduction of guanidine bases, and because he was able to reduce this rise by the administration of liver extract he postulated that its hypotensive action did not depend solely on vasodilatation, but that it also assisted the liver in destroying pressor bodies in the form of amino-acid waste products. Later (1926) in 100 patients with hypertension he reported that an immediate fall in the blood pressure could be obtained from liver extract injections, and that this effect was often conspicuous and lasted for several hours. MacDonald (1925) gave the results obtained from the treatment of 33 patients with hyperpiesia. Lautman (1926) reported a fall in blood pressure in 34 cases of hypertension following 10 to 24 daily injections of liver extract. Harrower (1926) recorded a fall in blood pressure in 40 cases of hypertension from the use of anabolin ( 1 to 4 tablets daily) by mouth. Burnett (1926) expressed his opinion that the hypotensive effects of liver extract depended mainly on the histamine which it contained, and in 1929, with Althausen and Kerr, he described favourable results from the use of intramuscular injections in 27 cases with hypertension. Willis (1930) has described the preparation and standardization of anabolin and has stated that it is free from choline and that histamine is only present in negligible quantities. When used intravenously in 150 cases of hyperpiesia it invariably lowered the blood pressure and produced symptomatic improvement, but the same favourable results were not obtained from its oral administration.

We submitted anabolin to a trial in 22 patients with hyperpiesia, and 
observed its effect in a daily dosage of 3 tablets by mouth during 35 test periods. A fall occurred during 6, conspicuous in 3 and moderate in 3 ; there was no change during 20 ; and a rise took place during 7, conspicuous in 4 and moderate in 3 . In 2 instances the effects could not be recorded because the patients failed to continue taking anabolin on account of dizziness.

Symptomatic improvement was recorded during 7 test periods on anabolin, but during 28 the symptoms either remained stationary or became aggravated.

Sex Hormones.-Steinach, Peczenik, and Kun (1938) investigated the action of male hormone preparations on male patients with hypertension, and noted a fall in the systolic pressure in 31 of 49 cases treated with androsterone benzoate or testosterone propionate. Symptomatic improvement also took place. In a further series small doses of œstradiol benzoate were added to the male hormone. They found that cases which proved refractory to the male hormone alone responded favourably to the combined preparation. Steinach and Kun (1937) believed that the male hormone was converted into an œstrogenic substance when injected into male patients, and they attributed clinical improvement in male patients with hypertension to the converted male hormone.

Perandren (male hormone) and œstrone (female hormone) were given consecutively by intramuscular injections of 1 c.c. twice weekly for three weeks in 8 patients with hyperpiesia, 4 of whom were males and 4 females. Frequent blood pressure readings were recorded, and comparing these with those obtained during control periods on a placebo mixture we concluded that neither preparation evoked any hypotensive effect.

\section{WEIGHT-REDUCING DIET IN HYPERPIESIA}

Embleton (1938) recorded a steady and lasting fall in blood pressure in 18 patients with hyperpiesia while taking a high-protein diet which caused reduction in the body weight. He mentioned, however, that transitory rises in the pressure took place on account of constipation or severe emotional strain. His claims were based on a comparison of subsequent blood pressure readings with the initial reading. The present investigation has convinced us of the necessity of discarding the first and sometimes even the second reading in order to avoid the fallacious deductions which inevitably result if these are accepted as values standard for the patient. In 28 out of 64 unselected cases of hyperpiesia in this series we found that the blood pressure at the second examination after placebo treatment did not vary by more than $10 \mathrm{~mm}$. from that recorded at the first examination, but in 36 cases a variation of more than $25 \mathrm{~mm}$. had occurred ; in 9 it had risen and in 27 it had fallen. Not only did a fall take place three times more often than a rise, but the extent of the fall was much greater than the rise ; thus only 3 cases showed a rise exceeding $40 \mathrm{~mm}$. and none exceeded $60 \mathrm{~mm}$., whereas among the 27 cases where a fall had taken place it was $40 \mathrm{~mm}$. or over in 11 cases and in 5 of these it was $60 \mathrm{~mm}$. or over.

We determined the effects of a reducing diet in 5 patients with hyperpiesia and obesity during a period when no active drugs were prescribed. The daily diet, providing for equal values of protein, fat and carbohydrate, had a calorie value of about 1168 calories, and was made up as follows : 
Breakfast : Tea with milk. Two eggs or a piece of fish or one thin rasher of bacon. Vita-weat biscuit. Butter (size of a cherry). Tomatoes or fresh fruit $\left(\frac{1}{4} \mathrm{lb}\right.$.).

Dinner : A good portion of lean meat or cheese. Plateful of green vegetables or salad. One small apple, orange, pear, or grapefruit. Vita-weat biscuit.

Tea : Tea with milk. One egg. Vita-weat biscuit and butter (size of a cherry).

Supper : A fair portion of steamed fish or lean meat or cheese. Plateful of green vegetables or salad. Vita-weat biscuit and butter (size of two cherries). One small apple, orange, pear, or grapefruit.

Sugar, cakes, pastries, puddings, jam, bread, potatoes, bananas, and fried food were not allowed.

A satisfactory reduction of body weight was always obtained within a short period and details of this and the blood pressure readings have been set out in charts (Figs. 3, 4, 5 and 6). When these results were compared with

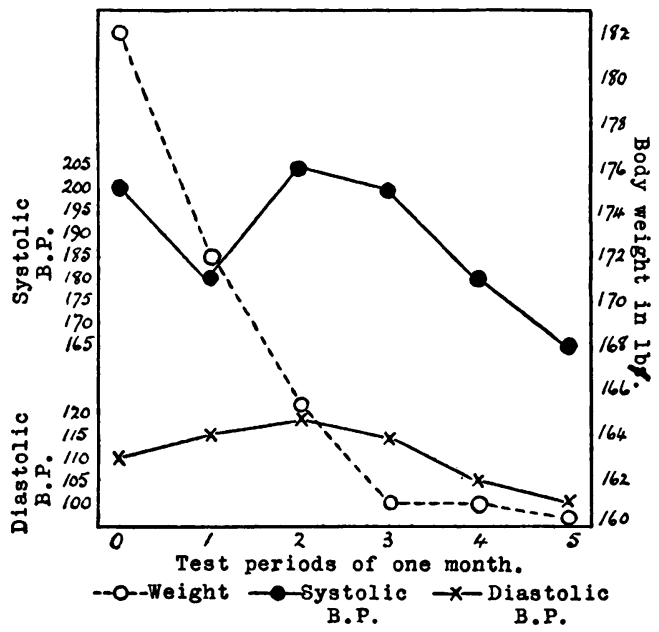

Fig. 3.-Blood pressure in a female, aged 59, with hyperpiesia, during treatment with a fat-reducing diet.

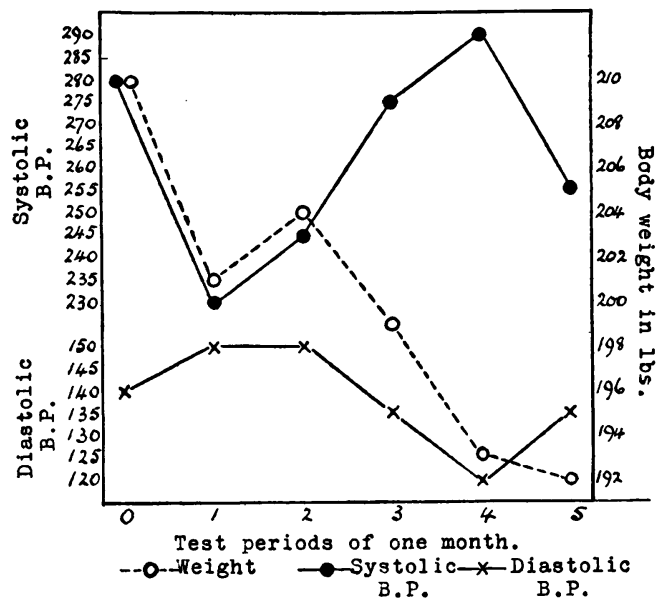

FIG. 4.-Blood pressure in a female, aged 53, with hyperpiesia, during treatment with a fat-reducing diet. 


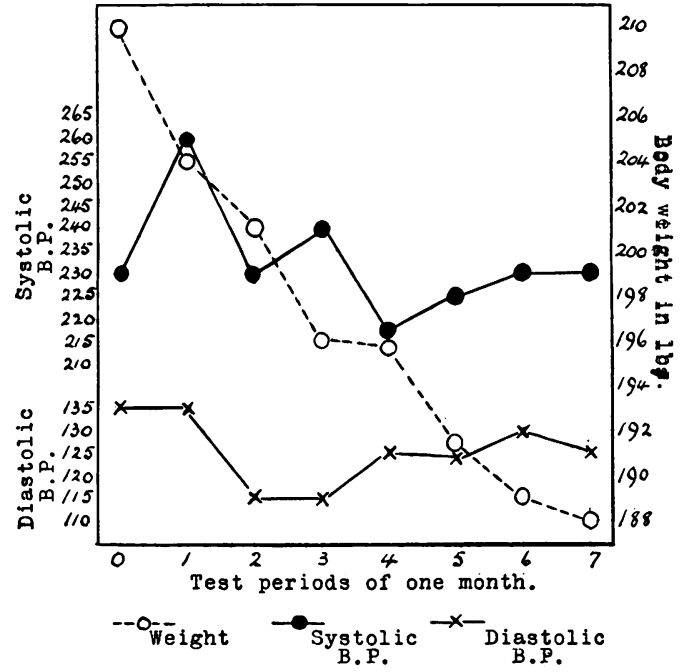

FIG. 5.-Blood pressure in a female, aged 48, with hyperpiesia, during treatment with a fat-reducing diet.

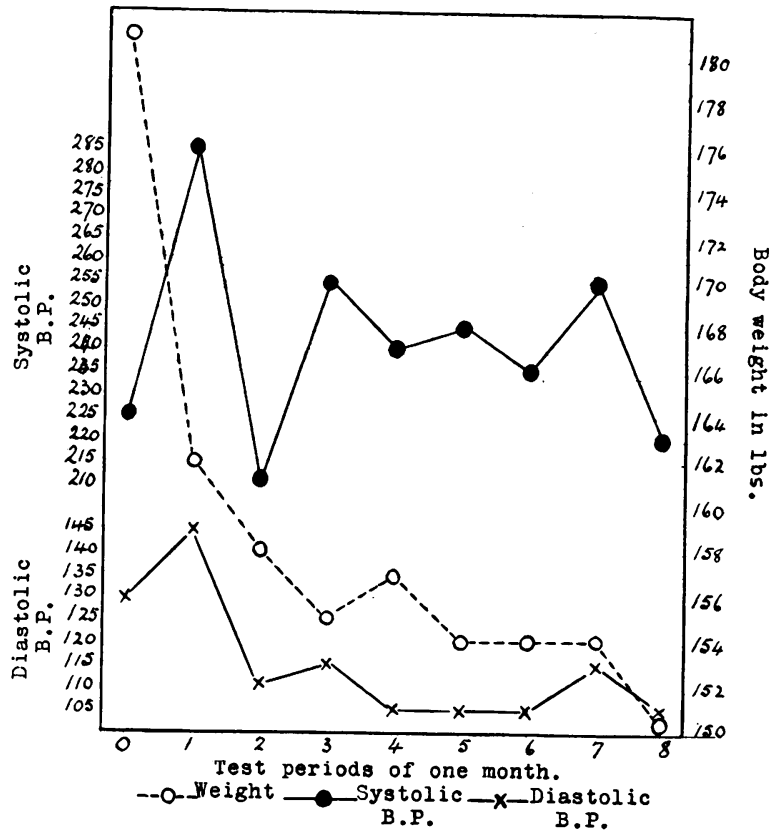

FIG. 6.-Blood pressure in a female, aged 68 , with hyperpiesia, during treatment with a fat-reducing diet. 
those obtained from the use of a placebo only (Fig. 1), we concluded that dietetic treatment which effected a considerable reduction in the body weight did not influence the blood pressure in patients with hyperpiesia, although symptomatic improvement from loss of weight usually took place. During the period when the weight was falling quickly and later when the reduced weight was being maintained the blood pressure showed a variation which we have come to regard as a normal occurrence in a patient with hyperpiesia (Fig. 1). Observations in these five obese patients undergoing dietetic treatment have in this way provided us with another opportunity of watching this natural variation.

\section{DISCUSSION OF RESULTS}

\section{Natural Variation in Blood Pressure}

Although we knew that the blood pressure fluctuates from time to time, becoming higher during periods of nervousness, as this investigation proceeded we came to realize more fully how great is the natural variation and how false would be the judgment of the hypotensive action of a drug if this were ignored. No drug should be credited with such properties unless it has exerted this effect to a greater extent than that which occurs naturally during a period on placebo treatment. Fig. 1 shows these periodic changes in the blood pressure during a time when a placebo medicine was the only form of treatment. Similar variations are seen in Figs. 2 to 6 in patients on a reducing diet and a placebo.

Again, the initial blood pressure, i.e. the first reading, is often so much higher than the standard for the individual patient that a disregard of this fact has led to a wrong estimate of the hypotensive properties of certain drugs. Thus among those patients in whom a second reading differed from the first by more than $25 \mathrm{~mm}$. while on placebo treatment there was a fall in three-quarters of the cases. Frequently the systolic value fell $40 \mathrm{~mm}$. and often more than $60 \mathrm{~mm}$. (see Table VIII). We attributed the higher initial readings to the

TABLE VIII

Change in the Blood Pressure at the Second Examination when taking a Simple Placebo Mixture

\begin{tabular}{|c|c|c|c|}
\hline \multirow{2}{*}{ Data } & \multicolumn{3}{|c|}{ Blood Pressure Change } \\
\hline & $\begin{array}{l}\text { No Change or } \\
\text { Change of less } \\
\text { than } 10 \mathrm{~mm} .\end{array}$ & Rise & Fall \\
\hline $\begin{array}{c}\text { Sixty-four patients } \\
\text { piesia }\end{array}$ & 28 & 9 & 27 \\
\hline $\begin{array}{l}\text { Change in systolic blood pressure } \\
\text { in } \mathrm{mm} \text {. }\end{array}$ & - & $\begin{array}{lll}15 & 15 & 25 \\
20 & 20 & 15 \\
40 & 45 & 50\end{array}$ & $\begin{array}{llllll}20 & 15 & 25 & 25 & 20 & 15 \\
15 & 25 & 25 & 20 & 20 & 20 \\
25 & 15 & 25 & 20 & 50 & 60 \\
75 & 40 & 40 & 40 & 65 & 65 \\
60 & 45 & 45 & & & \end{array}$ \\
\hline
\end{tabular}


excitement at the first clinical examination, and sought confirmation of this by recording the pressure continuously in 7 healthy subjects and in 7 patients with hyperpiesia until it assumed a constant and basic level as they rested on the examining couch. The extent of the fall and the time taken to reach this level is shown in Table IX. The effect of emotional disturbance on the blood

TABLE IX

The Fall in Blood Pressure to its Basic Level with Rest on an Examination Couch. The Blood Pressure was Recorded each Minute

\begin{tabular}{c|c|c|c}
\hline Case & $\begin{array}{c}\text { Initial State of the } \\
\text { Blood Pressure }\end{array}$ & $\begin{array}{c}\text { Extent of Fall of } \\
\text { Systolic Pressure in } \\
\text { mm. before reaching a } \\
\text { Constant Basic Level }\end{array}$ & $\begin{array}{c}\text { Time (in minutes) } \\
\text { taken to reach Basic } \\
\text { Level }\end{array}$ \\
\hline 1 & Raised & 20 & 6 \\
2 & Raised & 55 & 19 \\
3 & Raised & 30 & 5 \\
4 & Raised & 5 & 2 \\
5 & Raised & 10 & 6 \\
6 & Raised & 10 & 4 \\
7 & Raised & 10 & 7 \\
8 & Normal & 20 & 20 \\
9 & Normal & 15 & 2 \\
10 & Normal & 30 & 9 \\
11 & Normal & 5 & 1 \\
12 & Normal & 25 & 6 \\
13 & Normal & 10 & 4 \\
14 & Normal & 10 & 10 \\
\hline
\end{tabular}

pressure was next observed in patients at rest and just after a verbal explanation about amyl nitrite inhalation. A rise in the blood pressure invariably took place and within two minutes of the explanation (Table $X$ and Fig. 7). Such changes are of obvious importance in considering the effect of a drug.

TABLE $X$

The Rise of Systolic Blood Pressure after Explaining the Details connected WITH AMYL NitRite INHALATION

\begin{tabular}{c|c|c}
\hline Case & $\begin{array}{c}\text { Initial State of the } \\
\text { Blood Pressure }\end{array}$ & $\begin{array}{c}\text { Extent in mm. to which } \\
\text { the Systolic Blood } \\
\text { Pressure Rose within } \\
\text { Two Minutes of the } \\
\text { Explanation }\end{array}$ \\
\hline 1 & Raised & 25 \\
2 & Raised & 10 \\
3 & Raised & 25 \\
4 & Raised & 10 \\
5 & Raised & 10 \\
6 & Raised & 5 \\
7 & Raised & 10 \\
8 & Normal & 20 \\
9 & Normal & 20 \\
10 & Normal & 30 \\
11 & Normal & 25 \\
12 & Normal & 15 \\
13 & Normal & 15 \\
14 & Normal & 35 \\
15 & Normal & 15 \\
\hline
\end{tabular}




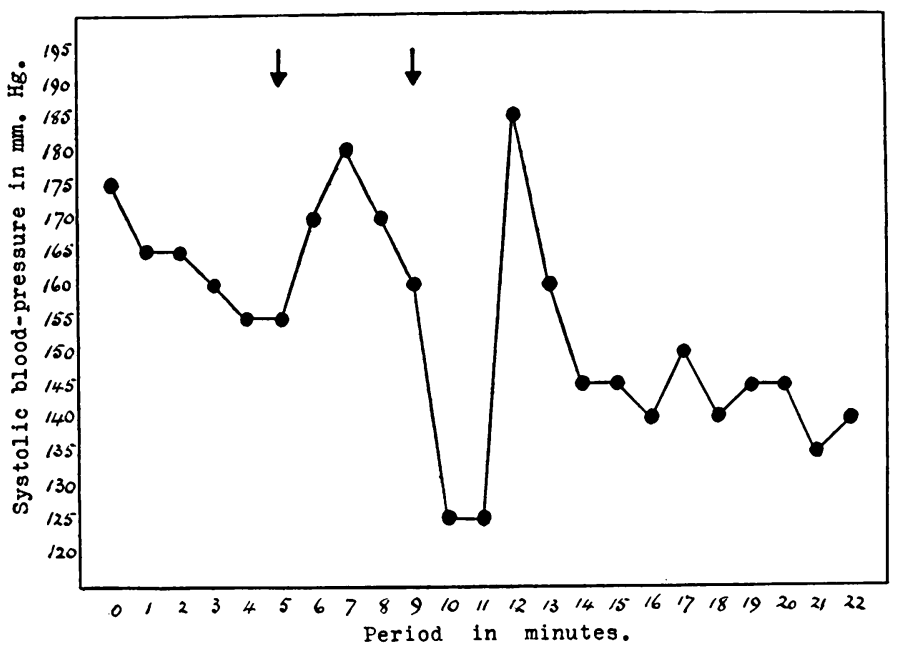

Fig. 7.-Showing the reaction of the blood pressure to emotional disturbance and to inhalation of amyl nitrite. The blood pressure, which has taken four minutes to fall to its basic level, rises following an explanation of the procedure of amyl nitrite inhalation, falls abruptly after the inhalation, and maintains a low level following a temporary and reactionary rise. The first arrow in the chart indicates the stage at which the explanation was made and the second arrow denotes the time of the inhalation.

\section{Effect of Drugs on the Blood Pressure}

Not until our records were completed did we examine the results critically, and then it was apparent that although these patients had been taking continuously the many reputed remedies none showed any clinical change nor any effective fall in blood pressure. It never assumed a value during treatment with any of the 33 remedies tried that was lower than the value recorded in the same patient when an inert placebo was exhibited. It is remarkable that even when considered statistically (see Table XI) in terms of hypotensive effects estimated from the relative incidence of the fall and rise in blood pressure while taking the different remedies, papaverine sulphate and chloral hydrate were the only two drugs producing collective results a trifle better than an inert placebo, and not enough to justify their routine use in hyperpiesia. No evidence was obtained to justify the prescribing of any of the tested preparations if the object is to reduce the blood pressure, for it has been shown here that none of them possesses this property under clinical conditions. The indiscriminate use of new and often expensive remedies for hypertension without first submitting them to a controlled clinical trial is to be deprecated. 


\section{Effect of Drugs on Symptoms}

The effects of a blood pressure variation were watched particularly where a rise or fall of more than $25 \mathrm{~mm}$. had taken place. During 64 test periods when this conspicuous change was a rise the symptoms improved in 36 per cent., were unchanged in 38 per cent. and were worse in 26 per cent. During 90 test periods when the change was a fall the symptoms improved in 34 per cent., were unchanged in 46 per cent. and were worse in 20 per cent. The symptoms in a patient with hyperpiesia, therefore, bear no relation to the height of his blood pressure at the time. It caused some surprise to find no improvement in such a high proportion of patients when the pressure had fallen conspicuously, and it caused greater surprise to find improvement in symptoms coinciding with a rise as often as with a fall in the blood pressure.

TABLE XI

Summarizing the Changes in Blood Pressure in Patients with Hyperpiesia DURING TeSt Periods While taking Different Medicines

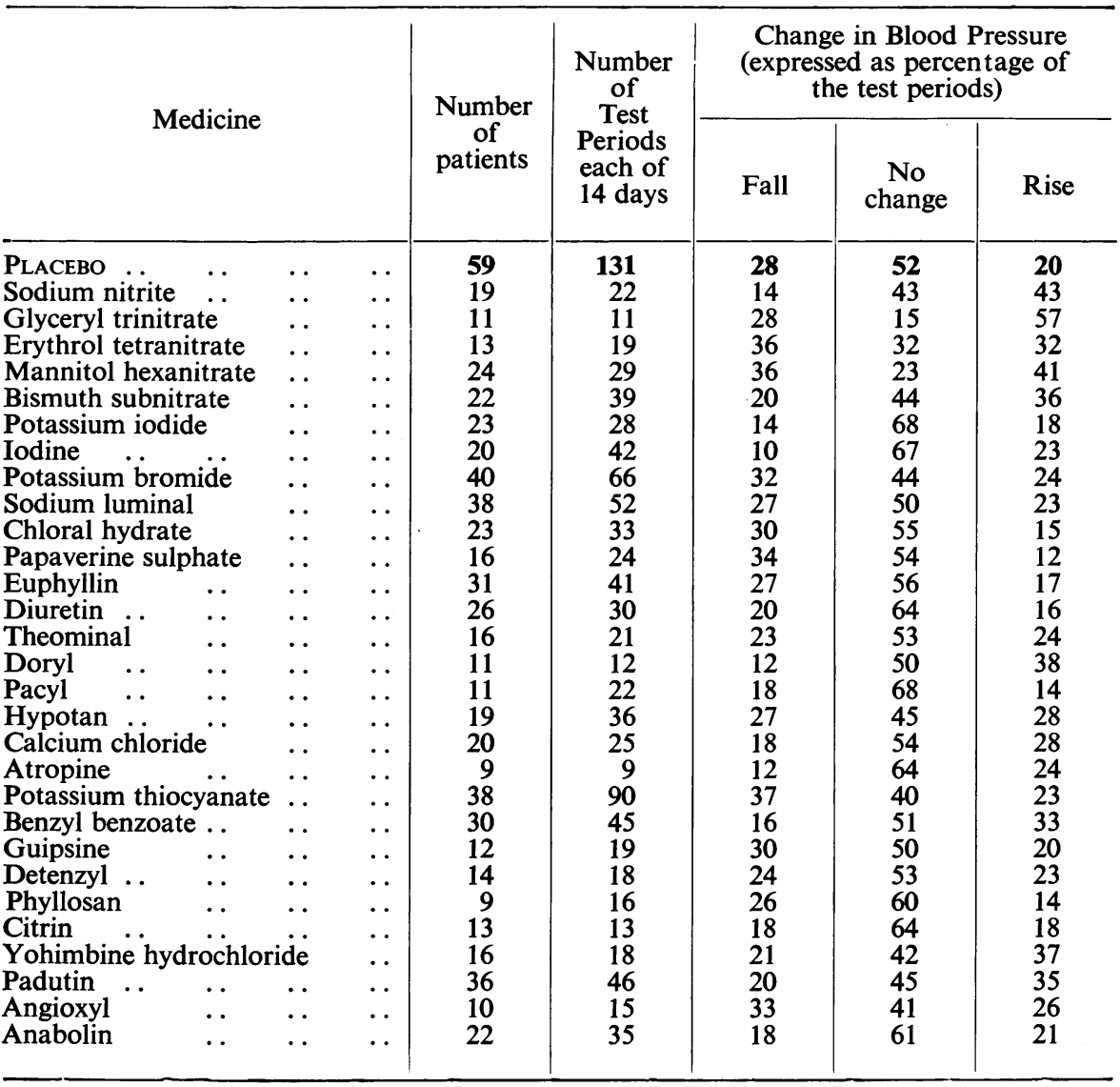


An estimate was made of the symptomatic improvement gained by patients under treatment with the various remedies. The improvement was always assessed by a comparison with progress shown during test periods on a placebo. Improvement greater than that shown during placebo treatment was only found in six of the active drugs, bismuth subnitrate, iodine and iodide, bromide, sodium luminal, theominal and potassium thiocyanate. Excepting bismuth subnitrate, they only proved slightly superior to a placebo. In patients manifesting nervousness, restlessness and sleeplessness, bromide, sodium luminal and theominal often ameliorated the symptoms, but without any associated effect on the blood pressure.

\section{SUMMARY AND CONCLUSIONS}

The effect of 33 preparations on the blood pressure and symptoms was watched in 70 patients with hyperpiesia (essential hypertension) over a period of eighteen months. The drugs or preparations were various and included nitrites, iodides, sedatives, xanthine and choline derivatives, vegetable extracts and hormones. Naturally it was not possible to test each remedy in every patient as some were accepted after the investigation had begun and a few failed to complete the whole course. Each medicine was prescribed in optimum doses for test periods of a fortnight, and at the end of each period the patient attended for re-examination, when the blood pressure was recorded under the same unvarying and standard conditions and any change in symptoms was noted.

When the basic pressure for each patient had been estimated from the first three observations, the hypotensive effect (or absence of effect) of a particular drug was often decided in individual patients at the end of a test period of 14 days, but as a rule each drug was given a second trial over longer intervals in a certain number of patients. To begin with, and later at irregular intervals, control test periods were instituted for each patient, when an inert placebo mixture was the only treatment given. In two patients the blood pressure was recorded throughout the investigation while taking a placebo of which the colour and flavour were the only variants. In five obese patients it was recorded while on a reducing diet and without drugs.

After allowance had been made for the tendency to obtain high blood pressure readings at the first and possibly at the second examination, and for the natural variation, and when the results from the tested drugs were compared with those from a placebo, we found that none of the 33 preparations produced hypotensive effects in patients with hyperpiesia. In regard to symptomatic improvement, only 6 of the drugs, namely bismuth subnitrate, iodine and iodide, bromide, sodium luminal, theominal and potassium thiocyanate, on an average relieved symptoms rather more than did the placebo. The sedative drugs seem to have value in temporarily relieving nervous symptoms when these were prominent. 
Although these results may surprise some, they will accord with the expectation and experience of many physicians. Admittedly, this paper deals with only a small section of the therapeutics of hyperpiesia, and it does not bear on the management of hypertensive heart disease including heart failure, where drug treatment can often be seen at its best. Our negative findings with drugs in uncomplicated hyperpiesia do not make it less desirable that the patient should remain under medical supervision. It is obvious that a patient should not regard his symptoms as closely related to the height of his blood pressure. Medical attention must be devoted to the alleviation of symptoms when they arise and to correcting faults in living, and particularly to the adoption of timely active measures when symptoms or signs of heart failure first appear.

Time will show whether surgical measures are a practicable means of lowering blood pressure and of lessening symptoms in hyperpiesia. Meantime a clearer insight into the origin of hypertension must precede its successful treatment with drugs.

We are grateful to Mr. C. H. Sykes, pharmacist to the hospital, who willingly co-operated with us throughout the investigation. Our thanks are due to Messrs. Ciba, Ltd., for supplying perandren and œstrone. We are indebted for financial assistance : one of us (W. E.) received a grant from the Medical Research Council, and the other (O. L.) held a scholarship from the Medical Research Council of Ireland, tenable under the direction of Professor Arthur Ellis of the Medical Unit, London Hospital. Dr. John Parkinson, Physician to the Cardiac Department, has helped us with advice and criticism.

\section{REFERENCES}

Abrami, M., Santenoise, M., and Bernal, M. (1933). Presse med., 41, 329.

Addison, W. L. T., and Clark, H. G. (1925). Canad. med. Ass. J., 15, 913.

Adson, A. W., and Allen, E. V. (1937). Proc. Mayo Clin., 12, 1.

Althausen, T. L., Kerr, W. J., and Burnett, T. C. (1929). Amer. J. med. Sci., 177, 398, and 178, 470.

Altnow, H. O., and O'Hare, J. P. (1937). Ann. intern. Med., $1,367$.

Ayman, D. (1931). J. Amer. med. Ass., 96, 1852. (1932). Ibid., 98, 545.

Barker, M. H. (1936). Ibid., 106, 762.

Barksdale, I. S. (1926). Amer. J. med. Sci., 171, 111.

Barrieu, M. (Nov. 1932). Bull. Soc. méd. de Paris.

Basch, E. (1924). Ther. d. Gegenw., 65, 398.

Bolotin, M. T. (1932). Illinois med. J., 62, 557.

Bruen, C. (1932). J. Lab. clin. Med., 18, 138.

- (1934). Amer. J. med. Sci., 188, 21.

Burgess, A. M. (1931). Ann. intern. Med., 5, 441.

Burnett, T. C. (1926). Amer. J. Physiol., 78, 449.

Busquet, H., and Vischniac, C. (1935). Progr. méd., Paris, 18, 738.

Carmichael, A. E., and Fraser, F. R. (1933). Amer. Heart J., 16, 263.

Dale, H. H. (1914). J. Pharmacol., 6, 147.

Dautrebande, L. (1933). Paris méd., 1, 398. 
Dawson of Penn (1925). Brit. med. J., 2, 1161.

Egloff, W. C., Hoyt, L. A., and O'Hare, J. P. (1931). J. Amer. med. Ass., 96, 1941.

Ellis, L. B., and Weiss, S. (1932). J. Pharmacol., 44, 235.

Fineberg, M. H. (1930). J. Amer. med. Ass., 94, 1822.

Fraser, F. R. (1938). Brit. med. J., 1,, 1249, 1293, and 1349.

Gager, L. T. (1928). J. Amer. med. Ass., 90, 82.

- (1930). Hypertension, Lond.

Ganter, G. (1928). Münch. med. Wschr., 5, 210.

Gargill, S. L., and Rudy, A. (1931). Amer. J. med. Sci., 181, 639.

Goldring, W., and Chassis, H. (1932). Arch. intern. Med., 49, 321.

Griffith, J. Q. (Jr.), and Lindauer, M. A. (1937). Amer. Heart J., 14, 710.

Gruber, C. M., and Shackelford, H. H. (1924). J. Lab. clin. Med., 9, 685. and Ecklund, A. M. (1925). Arch. intern. Med., 36, 366.

Harrower, H. R. (1926). Med. J. Rec., 124, 83.

Hay, J. (1931). Brit. med. J., $2,43$.

Kaiser, K. (1925). Klin. Wschr., 4, 1574.

Kreitmair, H. (1932). Arch.f. exp. Path. u. Pharmak., 164, 346.

Laubry, C., and Mougeot, A. (1921). Bull. Soc. méd. Hop. Paris, 45, 757.

- (1921). Abs. J. Amer. med. Ass., 77, 157.

Lautman, M. F. (1926). Med. J. Rec., 123, 751.

Leschke, E. (1930). Münch. med. Wschr., 36, 1524.

Lewis, T. (1937). Diseases of the Heart, Lond.

Lewy, F. H. (1928). Z. Klin. Med., 107, 72.

Livingstone, J. L. (1935). Lancet, 2, 961.

Loeper, A., and Lemaire, J. (July, 1930). C. R. Soc. Biol., Paris.

Macht, D. I. (1914). Bull. Johns Hopk. Hosp., 25, 278.

- (1916). Arch. intern. Med., 17, 786.

- (1918). J. Pharmacol., 11, 419.

- (1920). N.Y. St. J. Med., 112, 269.

Macdonald, W. J. (1925). Canad. med. Ass. J., 15, 697.

Major, R. H. (1924). J. Amer. med. Ass., 83, 81.

- (1924). Bull. Johns. Hopk. Hosp., 35, 140.

- (1925). Amer. J. med. Sci., 170, 228.

(1925). J. Amer. med. Ass., 85, 251.

(1926). Tr. Assoc. Amer. Phys., 41, 19.

Massie, E., Ethridge, C. B., and O'Hare, J. P. (1938). New Eng. J. Med., 219, 736.

Mattei, C. (1926). J. Amer. med. Ass., 87, 311.

Mattei, C., and Dias-Cavaroni, J. (1926). Presse méd., 34, 999.

Meakins, J., and Scriven, W. de M. (1931). Canad. med. Ass. J., 25, 285.

Mosenthal, H. O. (1933). Internat. Clin., 2, 145.

Nichols, B. J. (1925). Amer. J. med. Sci., 170, 735.

Norris, G. W., Bazett, H. C., and McMillan, T. M. (1927). Blood Pressure, 4th ed., Phil.

Nuzum, F. R., Elliot, H. A., and Bischoff, F. (1937). Arch. intern. Med., 59, 136.

Palmer, R. S., Silver, L. S., and White, P. D. (1929). New Eng. J. Med., 201, 709.

Palmer, R. S. (1932). Amer. J. med. Sci., 184, 473.

Parkinson, J. (1936). Index of Treatment, Lond., 11th ed.

Pauli, W. (1903). Münch. med. Wschr., 50, 153.

Scharpff, W. (1931). Dtsch. med. Wschr., 16, 675.

Seward, B. P. (1931). Virginia med. Monthly, 57, 788. (1932). Ibid., 59, 391.

Smith, A. G., and Rudolph, R. D. (1928). Canad. med. Ass. J., 19, 288.

Steinach, E., and Kun, H. (1937). Lancet, 2, 845.

Steinach, E., Peczenik, O., and Kun, H. (1938). Wein. klin. Wschr., 51, 102, and 134.

Stieglitz, E. J. (1927). J. Pharmacol., 32, 23.

- (1928). Ibid., 34, 407.

- (1930). J. Amer. med. Ass., 95, 842.

(1932). J. Pharmacol., 46, 343.

Weiss, S., and Ellis, B. (1933). Arch. intern. Med., 52, 105. 
White, P. D. (1937). Heart Disease, N.Y., 2nd ed.

Wilkinson, G. R. (1927). J. S. Carolina med. Ass., 23, 366.

Willis, J. D. (1930). Virginia med. Monthly, 57, 361.

Wolf, H. G. (1929). Arch. Neurol. Psychiat, Chicago, 22, 686.

Wolffe, J. B., and Digilio, V. A. (1937). J. Lab. clin. Med., 22, 374.

Zeiss, F. R., and Brams, W. A. (1930). Amer. Heart J., 5, 300. 